REVISTA CATALANA DE DRET AMBIENTAL Vol. VI Núm. 2 (2015): 1 - 26

-Crònica-

\title{
PERSPECTIVA DEL DERECHO DEL MEDIO AMBIENTE Y DE LAS POLÍTICAS AMBIENTALES DE LA UNIÓN EUROPEA
}

\author{
JORGE AGUdo GONZÁLEZ \\ Profesor titular de Derecho Administrativo \\ Universidad Autónoma de Madrid \\ LORENA TRUJILLO PARRA \\ Doctoranda \\ Universidad Autónoma de Madrid
}


Sumario: 1. Introducción. 2. Actividad de las instituciones en el ámbito de la política europea de medio ambiente. 2.1. Actos conjuntos del Consejo y del Parlamento Europeo. 2.2. Actos del Consejo. 2.3. Actos de la Comisión. A. Reglamentos. B. Reglamentos de Ejecución. C. Reglamentos delegados. D. Decisiones. E. Decisiones de Ejecución. F. Dictámenes y comunicaciones de la Comisión. 2.4. Otros. A. Comité de las Regiones. B. Comité Económico y Social Europeo.

\section{Introducción}

Desde finales de marzo hasta mediados del mes de octubre de 2015, la Unión Europea ha dictado menos actos de lo que es habitual en el marco de su política medioambiental. Como es común, gozan de mayor protagonismo, cuantitativamente, los actos dictados por la Comisión, especialmente los actos de ejecución y modificación de normas aprobadas con anterioridad, así como los actos jurídicos no vinculantes, destacando los dictámenes del Comité Económico y Social y de las Regiones. En relación con las materias objeto de los distintos actos jurídicos, destacan los relativos a la materia de pesca, así como a las sustancias autorizadas como aditivos para piensos animales.

La exposición, como venimos realizando, se ordenará en función de la institución emisora del acto jurídico, y dentro de la actividad de cada institución se atenderá, en la medida de lo posible, a una exposición temática por materias.

\section{Actividad de las instituciones en el ámbito de la política europea de medio ambiente}

\subsection{Actos conjuntos del Consejo y del Parlamento Europeo}

El consumo actual de bolsas de plástico produce unos altos niveles de basura dispersa y supone un uso ineficaz de los recursos. Asimismo, es previsible que su consumo aumente si no se toman medidas. Las bolsas de plástico dispersas provocan contaminación en el medio ambiente y agravan el problema generalizado de la presencia de basura en las masas de agua, lo que supone una amenaza para los ecosistemas acuáticos a nivel mundial. En este sentido, las bolsas de plástico con un espesor de menos de 50 micras, llamadas bolsas de plástico ligeras, representan la inmensa mayoría del número total de bolsas de plástico consumidas en la Unión; sin embargo, se reutilizan con menos frecuencia que las bolsas más gruesas. Por consiguiente, las bolsas de plástico ligeras se convierten en residuos más rápidamente y tienden a dispersarse como basura con mayor frecuencia debido a su reducido peso. Por todo ello, ocupan el primer lugar en la prevención de residuos. Para asegurar que las bolsas de plástico no 
vayan a parar al medio ambiente como basura, deben tomarse medidas adecuadas e informar a los consumidores sobre el tratamiento correcto de los residuos.

La Directiva 94/62/CE del Parlamento Europeo y del Consejo se adoptó para prevenir o reducir el impacto en el medio ambiente de los envases y de sus residuos. Sin embargo, aunque las bolsas de plástico son envases en el sentido de dicha Directiva, esta no contenía disposiciones específicas sobre el consumo de esas bolsas. A efectos de reducir los residuos generados por las bolsas de plástico ligeras, se adopta la Directiva (UE) 2015/720 del Parlamento Europeo y del Consejo, de 29 de abril de 2015, por la que se modifica la Directiva 94/62/CE en lo que se refiere a la reducción del consumo de bolsas de plástico ligeras.

Con el fin de impulsar una reducción sostenida del nivel de consumo medio de bolsas de plástico ligeras, es preciso que, en consonancia con los objetivos generales de la política de residuos de la Unión y con la jerarquía de residuos establecida en la Directiva 2008/98/CE del Parlamento Europeo y del Consejo, los Estados miembros tomen medidas para reducir de manera significativa el consumo de bolsas de plástico ligeras. Tales medidas de reducción han de tener en cuenta los niveles de consumo actuales de bolsas de plástico que presente cada Estado miembro, debiéndose exigir mayores esfuerzos allí donde esos niveles sean más altos y tomando en consideración las reducciones ya alcanzadas. Para supervisar los avances en la reducción del consumo de bolsas de plástico ligeras, es necesario que las autoridades nacionales faciliten información sobre su consumo con arreglo al artículo 12 de la Directiva 94/62/CE.

Las medidas que tomen los Estados miembros pueden incluir el uso de instrumentos económicos como los precios, los impuestos y las tasas, que han demostrado ser particularmente eficaces para reducir el consumo de bolsas de plástico, y restricciones a la comercialización, por ejemplo, prohibiciones con el carácter de excepciones a lo dispuesto en el artículo 18 de la Directiva 94/62/CE, siempre que dichas restricciones sean proporcionadas y no discriminatorias. Asimismo, los Estados miembros pueden optar por excluir las bolsas de plástico con un espesor de menos de 15 micras (bolsas de plástico muy ligeras), proporcionadas como envase primario de alimentos a granel, cuando sea necesario por razones higiénicas o cuando su uso ayude a prevenir el desperdicio de alimentos.

Por otro lado, la información a los consumidores ha demostrado desempeñar un papel decisivo en la consecución de cualquier objetivo de reducción del consumo de bolsas de 
plástico. Por ello, es necesario realizar esfuerzos a nivel institucional para que aumente la concienciación sobre el impacto medioambiental de las bolsas de plástico y acabar con la percepción que se tiene hoy en día de que el plástico es un material inocuo y barato. Para ello, es importante garantizar el reconocimiento a escala de toda la Unión de los distintivos o marcas para las bolsas de plástico biodegradables o compostables.

En otro orden de temas, la Directiva 2009/28/CE establece los criterios de sostenibilidad que deben cumplir los biocarburantes y biolíquidos para ser tenidos en cuenta a efectos del cumplimiento de los objetivos de la Directiva y para poder ser incluidos en regímenes de ayudas públicas. Esos criterios incluyen requisitos sobre los niveles mínimos de reducción de las emisiones de gases de efecto invernadero que deben alcanzar los biocarburantes y biolíquidos con respecto a los combustibles fósiles. La Directiva 98/70/CE establece, por su parte, criterios de sostenibilidad idénticos para los biocarburantes y exige a los proveedores de carburantes o energía que, a más tardar el 31 de diciembre de 2020, reduzcan como mínimo en un 6\% las emisiones de gases de efecto invernadero del ciclo de vida por unidad de energía de los combustibles utilizados en la Unión por los vehículos de carretera, las máquinas móviles no de carretera, los tractores agrícolas y forestales, así como las embarcaciones de recreo cuando no se hallen en el mar. La mezcla de biocarburantes es uno de los métodos de que disponen los proveedores de combustibles fósiles para reducir la intensidad de los gases de efecto invernadero de los combustibles fósiles suministrados.

La Directiva 2009/28/CE del Parlamento Europeo y del Consejo establece que cada Estado miembro debe velar por que la cuota de energía procedente de fuentes renovables en todos los tipos de transporte en 2020 sea como mínimo equivalente al $10 \%$ del consumo final de energía en el transporte en dicho Estado miembro. La mezcla de biocarburantes es uno de los métodos de que disponen los Estados miembros para alcanzar ese objetivo, y se espera que sea el que más contribuya a lograrlo. La Directiva 2009/28/CE también destaca la necesidad de la eficiencia energética en el sector del transporte, dada la probabilidad de que el objetivo porcentual obligatorio de la energía procedente de fuentes renovables sea cada vez más difícil de alcanzar de manera sostenible si sigue aumentando la demanda global de energía para el transporte.

Puesto que sería deseable alcanzar ya en 2020 un nivel significativamente más elevado de consumo de biocarburantes avanzados y biolíquidos en la Unión en comparación con las trayectorias actuales, se adopta la Directiva (UE) 2015/1513 del Parlamento Europeo 
y del Consejo, de 9 de septiembre de 2015, por la que se modifican la Directiva 98/70/CE, relativa a la calidad de la gasolina y el gasóleo, y la Directiva 2009/28/CE, relativa al fomento del uso de energía procedente de fuentes renovables.

En virtud de esta directiva, cada Estado miembro debe promover el consumo de biocarburantes avanzados y procurar alcanzar en su territorio un nivel mínimo de consumo de biocarburantes avanzados mediante la fijación de un objetivo nacional que no sea jurídicamente vinculante y que cada Estado se esfuerce en alcanzar como parte de la obligación de garantizar que la cuota de energía procedente de fuentes renovables en todos los tipos de transporte en 2020 sea como mínimo equivalente al $10 \%$ del consumo final de energía en transporte en ese Estado miembro. Los planes de los Estados miembros para alcanzar sus objetivos nacionales deben publicarse, cuando estén disponibles, con el fin de aumentar la transparencia y la previsibilidad con vistas al mercado.

También conviene que los Estados miembros informen a la Comisión sobre los niveles de consumo de biocarburantes avanzados en su territorio al fijar sus objetivos nacionales y sobre sus logros en la consecución de dichos objetivos nacionales en 2020, de los que debe publicarse un informe resumido, con el fin de evaluar si las medidas establecidas por la presente Directiva son eficaces para reducir el riesgo de emisiones de gases de efecto invernadero por el cambio indirecto del uso de la tierra mediante el fomento de biocarburantes avanzados.

Una mayor utilización de electricidad procedente de fuentes renovables es una manera de afrontar muchos de los desafíos que se presentan en el sector del transporte, así como en otros sectores energéticos. Por ello, es adecuado ofrecer incentivos adicionales para estimular el uso de electricidad procedente de fuentes renovables en el sector del transporte y aumentar los factores multiplicadores para el cálculo de la contribución de la electricidad procedente de fuentes renovables consumida por el transporte ferroviario electrificado y por los vehículos eléctricos de carretera con el fin de reforzar su despliegue y su penetración en el mercado. Resulta oportuno, por otro lado, considerar la posibilidad de adoptar medidas adicionales que fomenten la eficiencia energética y el ahorro de energía en el sector del transporte. 


\subsection{Actos del Consejo}

La Decisión (UE) 2015/798 del Consejo, de 11 de mayo de 2015, por la que se autoriza a la Comisión Europea a negociar, en nombre de la Unión Europea, enmiendas del Convenio de Viena para la protección de la capa de ozono y del Protocolo de Montreal relativo a las sustancias que agotan la capa de ozono, autoriza a la Comisión a negociar en nombre de la Unión, en las cuestiones que sean competencia de la Unión y con respecto a las cuales la Unión ha adoptado normas, unas enmiendas del Convenio de Viena para la protección de la capa de ozono y del Protocolo de Montreal relativo a las sustancias que agotan la capa de ozono en las conferencias de las partes en el Convenio y en las reuniones de las partes en el Protocolo en 2015 y 2016.

En este sentido, la Comisión llevará a cabo las negociaciones en consulta con el comité especial designado por el Consejo y de acuerdo con las directrices de negociación del Consejo que figuran en el anexo de la presente Decisión. Sin embargo, el Consejo podrá revisar en todo momento las directrices de negociación. A tal efecto, la Comisión informará al Consejo, al término de cada sesión de negociación, sobre el resultado de las negociaciones y, en su caso, sobre cualquier problema que pueda surgir durante estas.

Pasando a otro tema, como es bien sabido, el Protocolo de Kioto de la Convención Marco de las Naciones Unidas sobre el Cambio Climático (en adelante, Protocolo de Kioto) entró en vigor el 16 de febrero de 2005 y contiene compromisos de reducción de emisiones jurídicamente vinculantes. La Unión aprobó el Protocolo de Kioto mediante la Decisión 2002/358/CE del Consejo. La Unión y sus Estados miembros ratificaron el Protocolo de Kioto y acordaron cumplir sus compromisos del primer período de compromiso conjuntamente. Islandia ratificó el Protocolo de Kioto el 23 de mayo de 2002.

El Consejo, en su reunión de 15 de diciembre de 2009, acogió con satisfacción la solicitud de Islandia de cumplir conjuntamente con la Unión y sus Estados miembros los compromisos contraídos en el segundo período de compromiso e invitó a la Comisión a presentar una recomendación sobre la apertura de las negociaciones necesarias para la celebración de un acuerdo con Islandia que se ajustara a los principios y criterios establecidos en el paquete legislativo de la Unión sobre clima y energía.

En la Conferencia de Doha sobre el Clima, celebrada en diciembre de 2012, todas las partes en el Protocolo de Kioto acordaron la Enmienda de Doha, que establece el 
segundo período de compromiso del Protocolo de Kioto, que empezó el 1 de enero de 2013 y terminará el 31 de diciembre de 2020.

El Acuerdo se firmó el 1 de abril de 2015, de conformidad con la Decisión (UE) 2015/146 del Consejo. Con vistas a la rápida entrada en vigor de la Enmienda de Doha, antes de la Conferencia de las Naciones Unidas sobre el Clima que se celebrará en París a finales de 2015, para adoptar un nuevo instrumento jurídicamente vinculante para el período posterior a 2020 y para destacar el compromiso de la Unión, sus Estados miembros e Islandia de dar fuerza jurídica al segundo período de compromiso en un plazo oportuno, la Unión, los Estados miembros e Islandia deben tratar de ratificar, a más tardar en el tercer trimestre de 2015, la Enmienda de Doha y el Acuerdo. Como debe aprobarse el Acuerdo en nombre de la Unión, se adoptan la Decisión (UE) 2015/1340 del Consejo, de 13 de julio de 2015, relativa a la celebración, en nombre de la Unión Europea, del Acuerdo entre la Unión Europea y sus Estados miembros, por una parte, e Islandia, por otra, sobre la participación de Islandia en el cumplimiento conjunto de los compromisos de la Unión Europea, sus Estados miembros e Islandia en el segundo período de compromiso del Protocolo de Kioto de la Convención Marco de las Naciones Unidas sobre el Cambio Climático, y la Decisión (UE) 2015/1339 del Consejo, de 13 de julio de 2015, relativa a la celebración, en nombre de la Unión Europea, de la enmienda de Doha al Protocolo de Kioto de la Convención Marco de las Naciones Unidas sobre el Cambio Climático y al cumplimiento conjunto de los compromisos contraídos con arreglo al mismo.

\subsection{Actos de la Comisión}

\section{A. Reglamentos}

Con objeto de aplicar determinadas resoluciones adoptadas en la XVI Reunión de la Conferencia de las Partes de la Convención sobre el Comercio Internacional de Especies Amenazadas de Fauna y Flora Silvestres (CITES, 3-14 de marzo de 2013), deben modificarse algunas disposiciones del Reglamento (CE) núm. 865/2006 de la Comisión y añadirse otros nuevos. En particular, en consonancia con la Resolución Conf. CITES 16.8, deben introducirse disposiciones para simplificar el movimiento transfronterizo no comercial de especies. 
La experiencia adquirida con la aplicación de los reglamentos actuales ha puesto de manifiesto la conveniencia de modificar algunas de sus disposiciones para que la ejecución del Reglamento se realice de una forma armonizada y eficiente en toda la Unión. Se trata, en particular, de la primera introducción en la Unión de trofeos de caza de especímenes de algunas especies o poblaciones incluidas en el anexo B del Reglamento (CE) núm. 338/97, en relación con las cuales existe preocupación en cuanto a la sostenibilidad de su comercio o hay indicios de que una parte significativa de ese comercio es ilegal. En esos casos es necesario reforzar el control de las importaciones en la Unión y, por tanto, no deben aplicarse las excepciones previstas en el Reglamento (CE) núm. 338/97 para los efectos personales y los enseres domésticos. La experiencia adquirida con la aplicación del Reglamento (CE) núm. 865/2006 ha puesto de manifiesto, además, la necesidad de aclarar que los Estados miembros no deben expedir permisos de importación cuando, pese a su solicitud, no obtengan del país exportador o reexportador información satisfactoria en cuanto a la legalidad de los especímenes que van a importarse a la UE. Procede, por tanto, modificar el Reglamento (CE) núm. 865/2006 y, en consecuencia, se adopta el Reglamento (UE) 2015/870 de la Comisión, de 5 de junio de 2015, por el que se modifica, en lo relativo al comercio de especies de fauna y flora silvestres, el Reglamento (CE) núm. 865/2006, por el que se establecen disposiciones de aplicación del Reglamento (CE) núm. 338/97 del Consejo.

En relación con otra cuestión, se ha de poner de relieve que la Comisión ha consultado con los laboratorios de referencia de la Unión Europea en materia de residuos de plaguicidas la necesidad de adaptar determinados límites de determinación analítica. Estos laboratorios concluyeron que el progreso técnico permite, para ciertas mercancías, establecer límites más bajos de determinación analítica de diversas sustancias.

En los anexos del Reglamento (CE) núm. 396/2005 se fijaron los límites máximos de estos residuos (LMR). En el marco de un procedimiento de autorización del uso de determinados productos fitosanitarios, se presentaron varias solicitudes de modificación de estos límites. De conformidad con el procedimiento previsto en el Reglamento (CE) núm. 396/2005, los Estados miembros afectados evaluaron estas solicitudes y enviaron los correspondientes informes de evaluación a la Comisión. La Autoridad Europea de Seguridad Alimentaria estudió las solicitudes y los informes de evaluación, prestando especial atención a los riesgos para el consumidor $\mathrm{y}$, en su caso, para los animales, $\mathrm{y}$ 
emitió dictámenes motivados sobre los LMR propuestos y remitió dichos dictámenes a la Comisión y a los Estados miembros y los puso a disposición del público.

De acuerdo con los dictámenes motivados de la Autoridad Europea de Seguridad Alimentaria y de la Organización Mundial del Comercio, una vez consultados los socios comerciales de la Unión y teniendo en cuenta los factores pertinentes para la cuestión objeto de consideración, las modificaciones pertinentes de los LMR cumplen los requisitos del Reglamento (CE) núm. 396/2005.

En consecuencia, se admiten las solicitudes presentadas y para ello se adoptan los siguientes reglamentos:

- Reglamento (UE) 2015/868 de la Comisión, de 26 de mayo de 2015, por el que se modifican los anexos II, III y V del Reglamento (CE) núm. 396/2005 del Parlamento Europeo y del Consejo en lo relativo a los límites máximos de residuos de 2,4,5-T, barbano, binapacril, bromofós-etilo, canfecloro (toxafeno), clorbufam, cloroxurón, clozolinato, DNOC, dialato, dinoseb, dinoterb, dioxatión, óxido de etileno, acetato de fentina, hidróxido de fentina, flucicloxurón, flucitrinato, formotión, mecarbam, metacrifos, monolinurón, fenotrina, profam, pirazofos, quinalfós, resmetrina, tecnaceno $\mathrm{y}$ vinclozolina en determinados alimentos.

- Reglamento (UE) 2015/845 de la Comisión, de 27 de mayo de 2015, que modifica los anexos II y III del Reglamento (CE) núm. 396/2005 del Parlamento Europeo y del Consejo en lo relativo a los límites máximos de residuos de azoxistrobina, clorantraniliprol, ciantraniliprol, dicamba, difenoconazol, fenpiroximato, fludioxonil, glufosinato de amonio, imazapic, imazapir, indoxacarbo, isoxaflutol, mandipropamid, pentiopirad, propiconazol, pirimetanil, espirotetramat y trinexapac en determinados productos.

- Reglamento (UE) 2015/846 de la Comisión, de 28 de mayo de 2015, que modifica los anexos II y III del Reglamento (CE) núm. 396/2005 del Parlamento Europeo y del Consejo en lo relativo a los límites máximos de residuos de acetamiprid, ametoctradina, amisulbrom, bupirimato, clofentecina, etefon, etirimol, fluopicolide, imazapic, propamocarb, piraclostrobina y tau-fluvalinato en determinados productos.

- Reglamento (UE) 2015/896 de la Comisión, de 11 de junio de 2015, por el que se modifica el anexo IV del Reglamento (CE) núm. 396/2005 del Parlamento Europeo y del Consejo en lo que concierne al límite máximo de residuos de Trichoderma 
polysporum, cepa IMI 206039, Trichoderma asperellum (anteriormente, T. harzianum), cepas ICC012, T25 y TV1, Trichoderma atroviride (anteriormente, T. harzianum), cepas IMI 206040 y T11, Trichoderma harzianum, cepas T-22 e ITEM 908, Trichoderma gamsii (anteriormente, T. viride), cepa ICC080, Trichoderma asperellum, cepa T34, Trichoderma atroviride, cepa I-1237, geraniol, timol, sacarosa, sulfato férrico [sulfato de hierro (III)], sulfato ferroso [sulfato de hierro (II)] y ácido fólico en determinados productos.

- Reglamento (UE) 2015/1040 de la Comisión, de 30 de junio de 2015, que modifica los anexos II, III y V del Reglamento (CE) núm. 396/2005 del Parlamento Europeo y del Consejo, por lo que respecta a los límites máximos de residuos de azoxistrobina, dimoxistrobina, fluroxipir, metoxifenozida, metrafenona, oxadiargilo y tribenurón en determinados productos.

- Reglamento (UE) 2015/1101 de la Comisión, de 8 de julio de 2015, que modifica los anexos II y III del Reglamento (CE) núm. 396/2005 del Parlamento Europeo y del Consejo por lo que respecta a los límites máximos de residuos de difenoconazol, fluopicolide, fluopiram, isopirazam y pendimetalina en determinados productos.

- Reglamento (UE) 2015/1200 de la Comisión, de 22 de julio de 2015, que modifica los anexos II y III del Reglamento (CE) núm. 396/2005 del Parlamento Europeo y del Consejo, por lo que respecta a los límites máximos de residuos de amidosulfurón, fenhexamida, cresoxim-metilo, tiacloprid y trifloxistrobina en determinados productos.

Para terminar, y en relación con las disposiciones pesqueras que prohíben la pesca de determinadas especies en aguas internacionales y de la Unión Europea, se han dictado los siguientes reglamentos:

- Reglamento (UE) 2015/1059 de la Comisión, de 1 de julio de 2015, por el que se prohíbe la pesca de lenguado común en la zona IIIa; aguas de la Unión de las subdivisiones 22-32, por parte de los buques que enarbolan pabellón de Suecia.

- Reglamento (UE) 2015/1122 de la Comisión, de 8 de julio de 2015, por el que se prohíbe la pesca de lanzón en aguas de la Unión de la zona 1 de gestión del lanzón por parte de los buques que enarbolan pabellón de Dinamarca. 
- Reglamento (UE) 2015/1123 de la Comisión, de 8 de julio de 2015, por el que se prohíbe la pesca de lanzón en aguas de la Unión de la zona 6 de gestión del lanzón por parte de los buques que enarbolan pabellón de Dinamarca.

- Reglamento (UE) 2015/1124 de la Comisión, de 8 de julio de 2015, por el que se prohíbe la pesca de lanzón en aguas de la Unión de la zona 2 de gestión del lanzón por parte de los buques que enarbolan pabellón de Dinamarca.

- Reglamento (UE) 2015/1279 de la Comisión, de 22 de julio de 2015, por el que se prohíbe la pesca de aguja azul en el océano Atlántico por parte de los buques que enarbolan pabellón de España.

- Reglamento (UE) 2015/1280 de la Comisión, de 22 de julio de 2015, por el que se prohíbe la pesca de sable negro en aguas internacionales y de la Unión de las zonas VIII, IX y X por parte de los buques que enarbolan pabellón de España.

- Reglamento (UE) 2015/1281 de la Comisión, de 22 de julio de 2015, por el que se prohíbe la pesca de aguja blanca en el océano Atlántico por parte de los buques que enarbolan pabellón de España.

- Reglamento (UE) 2015/1282 de la Comisión, de 23 de julio de 2015, por el que se prohíbe la pesca de brosmio en aguas de la Unión e internacionales de las zonas $\mathrm{V}$, VI y VII por parte de los buques que enarbolan pabellón de España.

- Reglamento (UE) 2015/1283 de la Comisión, de 23 de julio de 2015, por el que se prohíbe la pesca de palometa en aguas de la Unión e internacionales de las zonas III, IV, V, VI, VII, VIII, IX, X, XII y XIV por parte de los buques que enarbolan pabellón de España.

- Reglamento (UE) 2015/1284 de la Comisión, de 23 de julio de 2015, por el que se prohíbe la pesca de carbonero en la zona VI, y en aguas de la Unión e internacionales de Vb, XII y XIV por parte de los buques que enarbolan pabellón de España.

- Reglamento (UE) 2015/1303 de la Comisión, de 28 de julio de 2015, por el que se prohíbe la pesca de rayas en aguas de la Unión de las zonas VIII y IX por parte de los buques que enarbolan pabellón de España.

- Reglamento (UE) 2015/1304 de la Comisión, de 28 de julio de 2015, por el que se prohíbe la pesca del lenguado común en las zonas VIIIa y VIIIb por parte de los buques que enarbolan pabellón de España. 
- Reglamento (UE) 2015/1305 de la Comisión, de 28 de julio de 2015, por el que se prohíbe la pesca de gallineta nórdica en aguas de la Unión e internacionales de la zona $\mathrm{V}$, y en aguas internacionales de las zonas XII y XIV por parte de los buques que enarbolan pabellón de España.

- Reglamento (UE) 2015/1306 de la Comisión, de 28 de julio de 2015, por el que se prohíbe la pesca de gallineta en aguas de Groenlandia de la zona NAFO $1 \mathrm{~F}$ y en las aguas de Groenlandia de las zonas V y XIV y en aguas internacionales de la zona de protección de la gallineta nórdica por parte de los buques que enarbolan pabellón de España.

- Reglamento (UE) 2015/1307 de la Comisión, de 28 de julio de 2015, por el que se prohíbe la pesca de eglefino en aguas de la Unión e internacionales de las zonas $\mathrm{Vb}$ y VIa por parte de los buques que enarbolan pabellón de España.

- Reglamento (UE) 2015/1347 de la Comisión, de 31 de julio de 2015, por el que se prohíbe la pesca de salmón del Atlántico en aguas de la Unión de las subdivisiones 22-31 por parte de los buques que enarbolan pabellón de Suecia.

- Reglamento de Ejecución (UE) 2015/1425 de la Comisión, de 24 de agosto de 2015, por el que se prohíben las actividades pesqueras de los cerqueros con pabellón o matrícula de Croacia, España, Francia, Italia y Malta que practican la pesca de atún rojo en el océano Atlántico, al este del meridiano $45^{\circ} \mathrm{O}$, y en el mar Mediterráneo.

- Reglamento (UE) 2015/1526 de la Comisión, de 11 de septiembre de 2015, por el que se prohíbe la pesca de gallineta nórdica en la zona NAFO 3M por parte de los buques que enarbolan pabellón de un Estado miembro de la Unión Europea.

- Reglamento (UE) 2015/1527 de la Comisión, de 11 de septiembre de 2015, por el que se prohíbe la pesca de gallineta nórdica en la zona NAFO 3M por parte de los buques que enarbolan pabellón de un Estado miembro de la Unión Europea.

- Reglamento (UE) 2015/1528 de la Comisión, de 11 de septiembre de 2015, por el que se prohíbe la pesca de noriegas y rayas en aguas de la Unión de la zona VIId por parte de los buques que enarbolan pabellón de Bélgica.

- Reglamento (UE) 2015/1529 de la Comisión, de 11 de septiembre de 2015, por el que se prohíbe la pesca de palometa en aguas de la Unión e internacionales de las 
zonas III, IV, V, VI, VII, VIII, IX, X, XII y XIV por parte de los buques que enarbolan pabellón de Irlanda.

- Reglamento (UE) 2015/1530 de la Comisión, de 11 de septiembre de 2015, por el que se prohíbe la pesca de pejerrey en aguas de la UE de las zonas III y IV por parte de los buques que enarbolan pabellón de Irlanda.

- Reglamento (UE) 2015/1531 de la Comisión, de 11 de septiembre de 2015, por el que se prohíbe la pesca de pejerrey en aguas de la Unión y aguas internacionales de las zonas V, VI y VII por parte de los buques que enarbolan pabellón de Irlanda.

- Reglamento (UE) 2015/1539 de la Comisión, de 15 de septiembre de 2015, por el que se prohíbe la pesca de sable negro en aguas de la Unión y aguas internacionales de las zonas V, VI, VII y XII por parte de los buques que enarbolan pabellón de Irlanda.

- Reglamento (UE) 2015/1540 de la Comisión, de 15 de septiembre de 2015, por el que se prohíbe la pesca de cangrejo de las nieves en aguas de Groenlandia de la zona NAFO 1 por parte de los buques que enarbolan pabellón de Irlanda.

- Reglamento (UE) 2015/1541 de la Comisión, de 15 de septiembre de 2015, por el que se prohíbe la pesca de fletán negro en aguas de la Unión de las zonas IIa y IV y en aguas de la Unión y aguas internacionales de las zonas Vb y VI por parte de los buques que enarbolan pabellón de Irlanda.

- Reglamento (UE) 2015/1542 de la Comisión, de 15 de septiembre de 2015, por el que se prohíbe la pesca de maruca azul en aguas de la Unión y aguas internacionales de las zonas Vb, VI y VII por parte de los buques que enarbolan pabellón de Irlanda.

- Reglamento (UE) 2015/1543 de la Comisión, de 15 de septiembre de 2015, por el que se prohíbe la pesca de gallineta nórdica en aguas de la Unión y aguas internacionales de la zona $\mathrm{V}$ y en aguas internacionales de las zonas XII y XIV por parte de los buques que enarbolan pabellón de Irlanda.

- Reglamento (UE) 2015/1544 de la Comisión, de 15 de septiembre de 2015, por el que se prohíbe la pesca de granadero de roca en aguas de la Unión y aguas internacionales de las zonas VIII, IX, X, XII y XIV por parte de los buques que enarbolan pabellón de Irlanda. 
- Reglamento (UE) 2015/1545 de la Comisión, de 15 de septiembre de 2015, por el que se prohíbe la pesca de besugo en aguas de la Unión y aguas internacionales de las zonas VI, VII y VIII por parte de los buques que enarbolan pabellón de Irlanda.

- Reglamento (UE) 2015/1546 de la Comisión, de 15 de septiembre de 2015, por el que se prohíbe la pesca de salmón atlántico en aguas de la Unión de las subdivisiones 22-31 por parte de los buques que enarbolan pabellón de Finlandia.

- Reglamento (UE) 2015/1547 de la Comisión, de 15 de septiembre de 2015, por el que se prohíbe la pesca de lanzón en aguas de la Unión de las zonas IIa, IIIa y IV; aguas de la Unión de las zonas de gestión del lanzón 1, 2, 3, 4, 5, 6 y 7 por parte de los buques que enarbolan pabellón de Alemania.

\section{B. Reglamentos de Ejecución}

En cuanto a los reglamentos de ejecución, podemos destacar especialmente las autorizaciones relativas al uso de diferentes sustancias como aditivo en piensos para todas las especies animales y, en menor medida, para su uso en biocidas.

El Reglamento (CE) núm. 1831/2003 regula el uso de aditivos en la alimentación animal y establece los motivos y procedimientos para su autorización. Se han presentado, en este ámbito, numerosas solicitudes de autorización de diferentes productos como aditivo en piensos. La Autoridad Europea de Seguridad Alimentaria concluyó que, en las condiciones de uso propuestas, estos productos no tienen efectos adversos para la salud animal, la salud humana ni el medio ambiente, y que pueden considerarse eficaces en lo que se refiere a su contribución para cumplir los requisitos de contenido en la alimentación de las especies animales. Por consiguiente, procede autorizar el uso de dichas sustancias según lo especificado en sus anexos. En esta materia, se han dictado los siguientes actos:

- Reglamento de Ejecución (UE) 2015/722 de la Comisión, de 5 de mayo de 2015, relativo a la autorización de la taurina como aditivo en piensos para cánidos, félidos, mustélidos y peces carnívoros.

- Reglamento de Ejecución (UE) 2015/723 de la Comisión, de 5 de mayo de 2015, relativo a la autorización de la biotina como aditivo en piensos para todas las especies animales. 
- Reglamento de Ejecución (UE) 2015/724 de la Comisión, de 5 de mayo de 2015, relativo a la autorización del acetato de retinilo, del palmitato de retinilo y del propionato de retinilo como aditivos en piensos para todas las especies animales.

- Reglamento de Ejecución (UE) 2015/861 de la Comisión, de 3 de junio de 2015, relativo a la autorización del yoduro de potasio, el yodato de calcio anhidro y el yodato de calcio anhidro granulado recubierto como aditivos en los piensos para todas las especies animales.

- Reglamento de Ejecución (UE) 2015/897 de la Comisión, de 11 de junio de 2015, relativo a la autorización del clorhidrato de tiamina y el mononitrato de tiamina como aditivos en piensos para todas las especies animales.

- Reglamento de Ejecución (UE) 2015/1020 de la Comisión, de 29 de junio de 2015, relativo a la autorización de un preparado de Bacillus subtilis (ATCC PTA-6737) como aditivo en piensos para gallinas ponedoras y especies menores de aves de corral ponedoras (titular de la autorización: Kemin Europa N.V.).

- Reglamento de Ejecución (UE) 2015/1043 de la Comisión, de 30 de junio de 2015, relativo a la autorización del preparado de endo-1,4-beta-xilanasa (EC 3.2.1.8) producido por Trichoderma citrinoviride Bisset (IM SD135) como aditivo en piensos para pollos de engorde, pavos de engorde, gallinas ponedoras, lechones destetados, cerdos de engorde y especies menores de aves de corral para engorde y para puesta, y por el que se modifican los Reglamentos (CE) núm. 2148/2004, (CE) núm. 828/2007 y (CE) núm. 322/2009 (titular de la autorización: Huvepharma NV).

- Reglamento de Ejecución (UE) 2015/1053 de la Comisión, de 1 de julio de 2015, relativo a la autorización del preparado de Enterococcus faecium DSM 10663/NCIMB 10415 como aditivo en piensos para terneros de cría, lechones, pollos de engorde, pavos de engorde, gatos y perros, y por el que se modifican los Reglamentos (CE) núm. 1259/2004, (CE) núm. 255/2005, (CE) núm. 1200/2005 y (CE) núm. 1520/2007 (titular de la autorización: Chevita Tierarzneimittel-GmbH).

- Reglamento de Ejecución (UE) 2015/1060 de la Comisión, de 2 de julio de 2015, relativo a la autorización de la betaína anhidra y del clorhidrato de betaína como aditivos en piensos para todas las especies animales.

- Reglamento de Ejecución (UE) 2015/1061 de la Comisión, de 2 de julio de 2015, relativo a la autorización de ácido ascórbico, fosfato de ascorbilo y sodio, fosfato 
de ascorbilo, calcio y sodio, ascorbato de sodio, ascorbato de calcio y palmitato de ascorbilo como aditivos en los piensos para todas las especies animales.

- Reglamento de Ejecución (UE) 2015/1103 de la Comisión, de 8 de julio de 2015, relativo a la autorización del beta-caroteno como aditivo en los piensos para todas las especies animales.

- Reglamento de Ejecución (UE) 2015/1105 de la Comisión, de 8 de julio de 2015, relativo a la autorización de un preparado de Bifidobacterium animalis ssp. animalis DSM 16284, Lactobacillus salivarius ssp. Salivarius DSM 16351 y Enterococcus faecium DSM 21913 como aditivo en la alimentación de pollitas para puesta y especies menores de aves de corral que no sean aves ponedoras, a la autorización de dicho aditivo para su uso en el agua de beber de los pollos de engorde, y por el que se modifica el Reglamento (UE) núm. 544/2013 en lo relativo al contenido máximo de dicho aditivo en el pienso completo y su compatibilidad con los coccidiostáticos (titular de la autorización: Biomin $\mathrm{GmbH}$ ).

- Reglamento de Ejecución (UE) 2015/1114 de la Comisión, de 9 de julio de 2015, relativo a la autorización de la L-valina producida por Escherichia coli como aditivo en piensos para todas las especies animales y por el que se modifica el Reglamento (CE) núm. 403/2009 y los Reglamentos de Ejecución (UE) núm. 848/2014 y (UE) núm. 1236/2014.

- Reglamento de Ejecución (UE) 2015/1152 de la Comisión, de 14 de julio de 2015, relativo a la autorización de extractos de tocoferol de aceites vegetales, extractos ricos en tocoferol de aceites vegetales (ricos en delta-tocoferol) y de alfa-tocoferol como aditivos en piensos para todas las especies animales.

- Reglamento de Ejecución (UE) 2015/1408 de la Comisión, de 19 de agosto de 2015, relativo a la autorización de DL-metionil-DL-metionina como aditivo en los piensos para peces y crustáceos.

- Reglamento de Ejecución (UE) 2015/1414 de la Comisión, de 20 de agosto de 2015, que modifica el Reglamento de Ejecución (UE) núm. 136/2012, por el que se autoriza el bisulfato de sodio como aditivo de piensos para mascotas y otros animales no productores de alimentos. 
- Reglamento de Ejecución (UE) 2015/1415 de la Comisión, de 20 de agosto de 2015, relativo a la autorización de la astaxantina como aditivo en los piensos para peces, crustáceos y peces ornamentales.

- Reglamento de Ejecución (UE) 2015/1416 de la Comisión, de 20 de agosto de 2015, relativo a la autorización del bisulfato de sodio como aditivo en piensos para todas las especies animales.

- Reglamento de Ejecución (UE) 2015/1489 de la Comisión, de 3 de septiembre de 2015, relativo a la autorización de los preparados de Lactobacillus plantarum NCIMB 30238 y Pediococcus pentosaceus NCIMB 30237 como aditivo en los piensos para todas las especies animales.

- Reglamento de Ejecución (UE) 2015/1490 de la Comisión, de 3 de septiembre de 2015, relativo a la autorización del preparado de carvacrol, cinamaldehído y oleorresina de Capsicum como aditivo en piensos para pollos de engorde (titular de la autorización Pancosma France S.A.S.).

- Reglamento de Ejecución (UE) 2015/1486 de la Comisión, de 2 de septiembre de 2015, relativo a la autorización de la cantaxantina como aditivo en piensos para determinadas categorías de aves de corral, peces ornamentales y aves ornamentales.

- Reglamento de Ejecución (UE) 2015/1747 de la Comisión, de 30 de septiembre de 2015, por el que se corrige el anexo del Reglamento (UE) núm. 26/2011, relativo a la autorización de la vitamina $\mathrm{E}$ como aditivo en piensos para todas las especies animales.

Por otro lado, la Comisión ha dictado los siguientes actos en relación con la aprobación de determinadas sustancias activas contenidas en biocidas:

- Reglamento de Ejecución (UE) 2015/985 de la Comisión, de 24 de junio de 2015, por el que se aprueba el uso de la clotianidina como sustancia activa existente en biocidas del tipo de producto 18 .

- Reglamento de Ejecución (UE) 2015/984 de la Comisión, de 24 de junio de 2015, por el que se aprueba el uso de la piritiona de cobre como sustancia activa existente en biocidas del tipo de producto 21 .

En relación con la actividad pesquera, de conformidad con el Reglamento (UE) núm. 1380/2013 del Parlamento Europeo y del Consejo, la política pesquera común deberá tener por objeto eliminar progresivamente los descartes, teniendo en cuenta los mejores 
dictámenes científicos disponibles, mediante la prevención y la reducción, en la medida de lo posible, de las capturas no deseadas. Así, una población con una amplia gama de clases anuales y suficiente reserva reproductiva es más resistente frente a la explotación $\mathrm{y}$, por lo tanto, tiene más probabilidades de alcanzar y mantener el nivel de rendimiento máximo sostenible. Debido a los desajustes en la selectividad, un intenso reclutamiento ha acabado en gran parte descartado en el mar Céltico y una mejor selectividad contribuirá a desarrollar las estructuras de clases plurianuales.

Un dictamen del Consejo Internacional para la Exploración del Mar (CIEM), recibido en junio de 2013, indica que no son suficientes las medidas adoptadas hasta la fecha para restablecer el estado de conservación de los gádidos y reclama recortes muy amplios de las posibilidades de pesca. En el caso del eglefino, por ejemplo, el CIEM afirma que "el reclutamiento en 2012 fue el más bajo de la serie temporal". En virtud de este dictamen, la conservación de las poblaciones de eglefino, bacalao y merlán en el mar Céltico exige una actuación inmediata. En este sentido, se adopta el Reglamento de Ejecución (UE) 2015/741 de la Comisión, de 8 de mayo de 2015, por el que se modifica el Reglamento de Ejecución (UE) núm. 737/2012 sobre la protección de determinadas poblaciones del Mar Céltico.

Por otro lado, la Comisión de Pesquerías del Atlántico Nororiental (CPANE), en su reunión anual de noviembre de 2013, adoptó varias recomendaciones sobre el control por el Estado rector del puerto y los formularios de informe de inspección, sobre formatos y protocolos de intercambio de datos y datos electrónicos, y sobre la futura cooperación multilateral en los caladeros. Por todo ello, resulta necesario incorporar dichas recomendaciones al derecho de la Unión. Procede, por tanto, modificar el Reglamento de Ejecución (UE) núm. 433/2012 y se adopta el Reglamento de Ejecución (UE) 2015/746 de la Comisión, de 11 de mayo de 2015, por el que se modifica el Reglamento de Ejecución (UE) núm. 433/2012, que establece disposiciones de aplicación del Reglamento (UE) núm. 1236/2010 del Parlamento Europeo y del Consejo por el que se establece un régimen de control y ejecución aplicable en la zona del Convenio sobre la futura cooperación multilateral en los caladeros del Atlántico Nororiental.

Asimismo, en otro orden de consideraciones, se ha de recordar que el capítulo $\mathrm{V}$ del Reglamento (CE) núm. 1005/2008 establece procedimientos para identificar los buques pesqueros que practiquen una pesca ilegal, no declarada y no reglamentada, para 
adoptar una lista de la Unión de tales buques y establecer las medidas que deben tomarse contra los buques pesqueros que figuren en esa lista. Todas las organizaciones regionales de ordenación pesquera prevén la elaboración y actualización periódica de estas listas de buques de pesca. A tales efectos, se dicta el Reglamento de Ejecución (UE) 2015/1296 de la Comisión, de 28 de julio de 2015, por el que se modifica el Reglamento (UE) núm. 468/2010 por el que se establece la lista de la UE de los buques que practican una pesca ilegal, no declarada y no reglamentada.

Igualmente, se ha dictado el Reglamento de Ejecución (UE) 2015/1316 de la Comisión, de 30 de julio de 2015, por el que se establece una excepción al Reglamento (CE) núm. 850/98 del Consejo con respecto al tamaño mínimo de referencia para la conservación de la lubina (Dicentrarchus labrax).

También en la materia de pesca, se ha de recordar que el Reglamento (CE) núm. 1967/2006 prohíbe el uso de artes remolcados a menos de tres millas náuticas de la costa o antes de la isóbata de cincuenta metros cuando esta profundidad se alcance a una distancia menor de la costa. Por ello, Francia presentó a la Comisión una solicitud de prórroga a la excepción para la utilización de jábegas en determinadas zonas marítimas situadas dentro de las aguas territoriales de Francia, sea cual sea la profundidad. La Comisión, tras analizar las circunstancias de ambos supuestos y el plan de gestión presentado por Francia para cada situación, autoriza la prórroga de esta excepción mediante el Reglamento de Ejecución (UE) 2015/1421 de la Comisión, de 24 de agosto de 2015, por el que se prorroga la excepción al Reglamento (CE) núm. 1967/2006 del Consejo en lo relativo a la distancia mínima de la costa y la profundidad de la pesca con jábegas en determinadas aguas territoriales de Francia (Languedoc-Rosellón y Provenza-Alpes-Costa Azul).

Por último, en materia de fauna y flora, la Comisión, de acuerdo con el Reglamento (CE) núm. 338/97, puede restringir la introducción de especímenes de determinadas especies en la Unión de acuerdo con las condiciones e informaciones aportadas por un grupo científico específico que estudia la repercusión en la fauna y flora europea de la introducción de especies. En este sentido, basándose en información reciente, el Grupo de Revisión Científica ha llegado a la conclusión de que el estado de conservación de algunas especies adicionales incluidas en el anexo B del Reglamento (CE) núm. 338/97 se vería seriamente afectado si no se prohibiera su introducción en la Unión desde ciertos países de origen. Debe, por lo tanto, prohibirse la introducción en la Unión de 
especímenes del género siguiente: Scolymia spp. de Tonga. Sin embargo, no debe seguir prohibiéndose la introducción en la Unión de especímenes de las especies siguientes: Hippopotamus amphibius de Camerún, Gambia, Níger, Nigeria, Sierra Leona y Togo; Crocodylus niloticus de Madagascar; Catalaphyllia jardinei, Euphyllia cristata, Plerogyra sinuosa, Plerogyra turbida, Eguchipsammia fistula, Heliofungia actiniformis, Hydnophora microconos, Blastomussa wellsi, Scolymia vitiensis y Trachyphyllia geoffroyi de Indonesia. Por ello, se adopta el Reglamento de Ejecución (UE) 2015/736 de la Comisión, de 7 de mayo de 2015, por el que se prohíbe la introducción en la Unión de especímenes de determinadas especies de fauna y flora silvestres.

\section{Reglamentos delegados}

Se dicta el Reglamento Delegado (UE) 2015/1341 de la Comisión, de 12 de marzo de 2015, por el que se modifica el Reglamento (UE) núm. 1236/2010 del Parlamento Europeo y del Consejo, por el que se establece un régimen de control y ejecución aplicable en la zona del Convenio sobre la futura cooperación multilateral en los caladeros del Atlántico Nororiental. En su reunión anual de noviembre de 2013, la Comisión de Caladeros del Atlántico Nororiental (CPANE) adoptó la Recomendación 9:2014, que modifica los artículos 39, 40, 41 y 45 del régimen, relativos, respectivamente, a la entrada en puerto, a la inspección en puerto, a los desembarques y transbordos, y a las medidas de seguimiento relativas a los buques que practican la pesca ilegal, no declarada y no reglamentada (“pesca INDNR"). En la misma reunión anual, la CPANE adoptó la Recomendación 11:2014, que modifica el artículo 11 del régimen sobre el sistema de localización de buques, y la Recomendación 14:2014, que modifica el artículo 14 del régimen en lo que respecta a la comunicación de los informes y mensajes a la Secretaría de la CPANE.

\section{Decisiones}

Se ha llevado a cabo una evaluación que confirma la pertinencia e idoneidad de los criterios ecológicos actuales, así como de los requisitos de evaluación y comprobación correspondientes, establecidos mediante las decisiones 2009/568/CE, 2011/333/UE, 2011/381/UE, 2012/448/UE y 2012/481/UE. Habida cuenta de que los procesos de revisión de los criterios ecológicos actuales y los requisitos de evaluación y 
comprobación correspondientes establecidos en esas decisiones se iniciarán en 2015, conviene prorrogar la vigencia de dichos criterios ecológicos y requisitos de evaluación y comprobación correspondientes hasta el 31 de diciembre de 2018. En este sentido, se dicta la Decisión (UE) 2015/877 de la Comisión, de 4 de junio de 2015, por la que se modifican las Decisiones 2009/568/CE, 2011/333/UE, 2011/381/UE, 2012/448/UE y 2012/481/UE con objeto de prorrogar la vigencia de los criterios ecológicos para la concesión de la etiqueta ecológica de la UE a determinados productos [notificada con el número C (2015) 3641].

La Decisión 2014/312/UE de la Comisión establece un período transitorio para que los fabricantes cuyos productos hayan obtenido la etiqueta ecológica de la UE para pinturas y barnices de interior y exterior dispongan de tiempo suficiente para adaptar sus productos de forma que cumplan los criterios y requisitos revisados. No obstante, los Estados miembros informaron a la Comisión de que no iban a poder verificar los productos con etiqueta ecológica en el plazo establecido de doce meses debido al elevado número de productos y requisitos adicionales. Se requiere un período adicional para garantizar una transición fluida. Sin embargo, expertos técnicos informaron a la Comisión y algunos Estados miembros de que la redacción actual de algunas definiciones contenidas en dicha Decisión no es clara, tal y como sucede con el término "sistema polar". A tales efectos, sobre la base de los debates mantenidos en las reuniones del Comité de Etiquetado Ecológico de la Unión Europea y del foro de organismos competentes, de noviembre de 2014, se decide adoptar la Decisión (UE) 2015/886 de la Comisión, de 8 de junio de 2015, que modifica la Decisión 2014/312/UE, por la que se establecen los criterios ecológicos para la concesión de la etiqueta ecológica de la UE a las pinturas y barnices de interior y exterior [notificada con el número C(2015) 3782], con el fin de aclarar las definiciones que se prestan a una interpretación errónea.

\section{E. Decisiones de Ejecución}

El fabricante Porsche AG ("el solicitante") presentó una solicitud de aprobación de una función de "navegación a vela" como tecnología innovadora el 13 de octubre de 2014. La solicitud se refiere a la función de "navegación a vela" de Porsche AG. La tecnología innovadora es una estrategia de control inteligente de la caja de cambios automática que permite utilizar un modo de conducción en el que el vehículo circula mientras el motor 
de combustión está desconectado de las ruedas (es decir, el embrague está desacoplado). Durante el modo de conducción de "navegación a vela", el motor está al ralentí, pero se garantiza el funcionamiento de los equipos auxiliares (por ejemplo, el generador, el compresor o la bomba de agua). Además, en la "navegación a vela", la energía cinética y potencial del vehículo se utiliza directamente para superar la resistencia al desplazamiento $\mathrm{y}$, en consecuencia, para reducir el consumo de combustible. El solicitante ha demostrado que la función de "navegación a vela" del tipo descrito cumple y satisface todos los requisitos previstos en el Reglamento 443/2009 del Parlamento Europeo y del Consejo, por lo que se dicta la Decisión de Ejecución (UE) 2015/1132 de la Comisión, de 10 de julio de 2015, relativa a la aprobación, de conformidad con el Reglamento (CE) núm. 443/2009 del Parlamento Europeo y del Consejo, de la función de "navegación a vela" como tecnología innovadora para la reducción de las emisiones de $\mathrm{CO}_{2}$ de los turismos.

En mayo de 2015, Polonia notificó casos de peste porcina africana en jabalíes (en la gmina de Michalowo), seguida por Lituania (en los rajono savivaldybe de Prienai y Kèdainiai) y Estonia (en el vald de Türi), situados en determinadas zonas.

Al evaluar los riesgos que representa la situación zoosanitaria de Estonia, Lituania y Polonia en cuanto a la peste porcina africana, debe tenerse en cuenta la evolución de la actual situación epidemiológica en la Unión al respecto. Con el fin de hacer más específicas las medidas de control zoosanitarias y de impedir la propagación de la peste porcina africana, así como de evitar toda perturbación innecesaria del comercio dentro de la Unión y de impedir barreras injustificadas al comercio de terceros países, procede modificar la lista de la Unión de las zonas sujetas a las medidas de control zoosanitarias establecidas en el anexo de la Decisión de Ejecución 2014/709/UE con el fin de tener en cuenta la actual situación zoosanitaria de esos tres países en relación con esa enfermedad. Se dicta, por lo tanto, la Decisión de Ejecución (UE) 2015/1169 de la Comisión, de 14 de julio de 2015, por la que se modifica el anexo de la Decisión 2014/709/UE, sobre medidas de control zoosanitarias relativas a la peste porcina africana en determinados Estados miembros, en lo que respecta a las entradas correspondientes a Estonia, Lituania y Polonia. Así, se modifican las zonas de las partes I y II correspondientes a Estonia, Lituania y Polonia.

Sin embargo, en agosto de 2015 se notificaron varios brotes de peste porcina africana por Estonia, Letonia y Lituania, por lo que se dicta la Decisión de Ejecución (UE) 
2015/1405 de la Comisión, de 18 de agosto de 2015, que modifica el anexo de la Decisión de Ejecución 2014/709/UE, sobre medidas de control zoosanitarias relativas a la peste porcina africana en determinados Estados miembros, en lo que respecta a las entradas correspondientes a Estonia, Letonia y Lituania.

F. Dictámenes y comunicaciones de la Comisión

Entre los dictámenes y comunicaciones dictados por la Comisión, cabe destacar:

- Dictamen de la Comisión, de 22 de mayo de 2015, sobre el plan de evacuación de residuos radiactivos procedentes del edificio de reagrupamiento de la instalación CIRES, en Francia.

- Dictamen de la Comisión, de 22 de junio de 2015, sobre el plan de evacuación de los residuos radiactivos resultantes del desmantelamiento del reactor reproductor rápido Phénix, situado en Marcoule, Francia.

- Dictamen de la Comisión, de 24 de junio de 2015, sobre el plan de evacuación de residuos radiactivos procedentes de la planta local de tratamiento de lodos de Sellafield, situada en el Reino Unido.

- Comunicación de la Comisión en el marco de la aplicación de la Directiva 2009/128/CE del Parlamento Europeo y del Consejo, de 21 de octubre de 2009, por la que se establece el marco de la actuación comunitaria para conseguir un uso sostenible de los plaguicidas (2015/C 196/02).

\subsection{Otros}

\section{A. Comité de las Regiones}

El Comité de las Regiones Europeo adopta el Dictamen de Oportunidades para un uso más eficiente de los recursos en el sector de la construcción (2015/C 195/06), en el cual respalda totalmente el intento de la Comisión Europea de avanzar en el desarrollo de objetivos e indicadores comunes como base para unas normas comunes europeas relativas a un uso eficiente de los recursos en el sector de la construcción a fin de incrementar la coordinación y la coherencia entre las políticas. Los entes locales y regionales son socios clave a la hora de promover un uso más eficiente de los recursos, 
habida cuenta de su contribución al desarrollo sostenible a través de sus efectos positivos en el medio ambiente, el clima, la economía y la sociedad. Asimismo, estos entes pueden actuar con instrumentos como la compra pública verde, impulsando el mercado de productos elaborados a partir de residuos de construcción y demolición. Y muestra, por tanto, su preocupación porque en esta comunicación la Comisión tampoco aborda el papel de los entes locales y regionales, aunque el Comité de las Regiones ha llamado la atención sobre este aspecto en dictámenes elaborados sobre temas similares.

Entiende que entre los problemas básicos se encuentran que los residuos reciclables de construcción y demolición de edificios terciarios se descarguen a menudo en vertederos sin evaluar previamente la viabilidad económica de su recogida y reciclado; la actuación de los poderes públicos en este sector, pues deberían establecer el marco para que los clientes, los contratistas y los promotores del sector de la construcción lleven a cabo una transición hacia prácticas respetuosas con el medio ambiente, dado que la fase de construcción es crucial para el rendimiento medioambiental de cualquier edificio a lo largo de su ciclo de vida; y la necesidad de aclarar que los materiales procedentes de la demolición pueden proceder tanto de la demolición completa de la edificación como de su rehabilitación, por lo que es necesario precisar que el concepto de demolición incluye la demolición parcial del edificio empleada en la rehabilitación.

Para terminar, considera que los líderes políticos tienen que ser conscientes de que una posible transformación del sector de la construcción requiere voluntad política y un fuerte espíritu de liderazgo en los niveles superiores de las administraciones locales y regionales. Igualmente, se hace hincapié no solo en los beneficios medioambientales, sino también en los beneficios económicos y sociales que se derivan de los edificios sostenibles con respecto a los costes de construcción y mantenimiento, y considera que es importante, asimismo, prestar especial atención a los problemas específicos de las regiones rurales y las ciudades pequeñas y medianas.

También se adopta el Dictamen del Comité de las Regiones Europeo - Mejorar la protección del medio marino (2015/C 260/02), que subraya la importancia fundamental de que la Unión Europea disponga de una política marítima integrada. Las zonas marítimas de Europa y sus costas son cruciales para el bienestar y la prosperidad de sus ciudadanos, ya que constituyen las rutas comerciales europeas, regulan su clima y sirven de fuente de alimentos, energía y recursos, además de ser los lugares preferidos para residencia y ocio. El buen estado medioambiental de los mares y océanos es un 
componente clave de la sostenibilidad de la vida, también fuera del medio marino. Además, se expresa la profunda preocupación por el hecho de que en la actualidad los mares europeos no gocen de un "buen estado medioambiental"; en concreto, porque muchas poblaciones de peces siguen siendo explotadas por encima de los niveles de rendimiento máximo sostenible; por los vertidos y la concentración de nutrientes, sustancias peligrosas y desechos; por el hecho de que la cantidad de especies alóctonas y de vertidos "sin sustancia" (ruido, luz y calor) todavía se sitúen por encima de los límites ecológicamente aceptables; y por la presión creciente que el cambio climático ejerce sobre los ecosistemas marinos, incluidos los costeros.

En relación con la Directiva Marco sobre la Estrategia Marina (DMEM), reconoce su importancia como pilar medioambiental de la política marítima integrada de la UE, que establece el objetivo vinculante de restaurar un "buen estado medioambiental" para 2020. Y recuerda y pide a los Estados miembros que, en lo sucesivo, cuando se aplique la Directiva, las excepciones que se mencionan en la DMEM se interpreten de forma restrictiva al objeto de no poner en peligro la consecución de un buen estado medioambiental. Asimismo, insta a los Estados miembros a que, cuando elaboren y apliquen los programas de medidas, tengan en cuenta tanto los principios del enfoque basado en el ecosistema como el principio de precaución y el principio de que quien contamina paga, y propone una serie de medidas que pueden ayudar a mejorar la protección del medio marino: medidas de protección de la biodiversidad, las redes tróficas y el suelo marino para protegerse frente a las especies alóctonas y para proteger las especies explotadas comercialmente; medidas contra la eutrofización y de reducción de los contaminantes; entre otras. Asimismo, insta a aplicar tales medidas con firmeza, teniendo en cuenta las distintas situaciones de partida y las características específicas de las diferentes regiones marinas, y garantizando su proporcionalidad, rentabilidad y viabilidad.

\section{B. Comité Económico y Social Europeo}

El Comité Económico y Social Europeo ha adoptado el Dictamen sobre "El desarrollo del sistema de gobernanza propuesto en el contexto del marco de actuación en materia de clima y energía hasta el año 2030" (2015/C 291/02). El marco de actuación en materia de clima y energía de la UE se asienta en un conjunto sustancial de legislación previa, transpuesta en parte de forma incompleta y aplicada ineficazmente. Sin 
embargo, materializar la Unión de la Energía exigirá la adopción de nueva legislación y, en particular, su aplicación rigurosa. Es esencial disponer de un marco de gobernanza sólido. La legislación es solo el principio, pues la clave del éxito radica en la gobernanza. La aplicación de las políticas exige el compromiso, la participación, la implicación y la buena voluntad de todas las partes interesadas. El tipo de gobernanza más eficaz es aquel en el que acordar los métodos para determinar y aplicar el objetivo se considera una empresa conjunta en la que participan todas las partes interesadas. En consecuencia, el Comité Económico y Social Europeo (en adelante, CESE) formula las recomendaciones siguientes:

- Un diálogo estructurado entre todas las partes interesadas deberá integrarse en el proceso de gobernanza si se pretenden mitigar los obstáculos sociales a las medidas reglamentarias y políticas, y apoyar cambios en los comportamientos y actitudes de los ciudadanos.

- Articular y desarrollar un liderazgo político claro para establecer y participar en un diálogo global entre las partes interesadas afectadas y lograr el compromiso de las instituciones legislativas de la UE con las cuestiones relacionadas con la transición energética (por ejemplo, clima, seguridad y justicia social), a modo de proceso de apoyo y acompañamiento paralelo a la Unión de la Energía y a la lucha europea contra el cambio climático.

- El CESE aboga por un diálogo con los interlocutores sociales para garantizar una transición energética que vincule la dimensión medioambiental con las preocupaciones sociales.

- Todo ello debería adoptar la forma de un diálogo europeo sobre la energía que genere confianza y permita una representación equilibrada de todas las partes interesadas para intercambiar información, expresar puntos de vista e influir en la elaboración de políticas sobre temas energéticos.

- En concreto, se insta al Consejo Europeo y al Parlamento a que, cuando examinen el paquete sobre la Unión de la Energía, adopten, con líneas de acción, las medidas que figuran en el punto 6 del presente Dictamen, en el que se aborda la puesta en marcha de un diálogo europeo sobre la energía para apoyar el proceso de gobernanza. 
- Para terminar, este diálogo se organizará en el marco de un foro específico que permita la participación de todas las partes interesadas.

Se adopta, asimismo, el Dictamen del Comité Económico y Social Europeo sobre la "Propuesta de Reglamento del Parlamento Europeo y del Consejo sobre requisitos relativos a límites de emisiones y homologación de tipo para motores de combustión interna que se instalen en máquinas móviles no de carretera" [COM(2014) 581 final — 2014/0268 (COD)] (2015/C 251/06). El Comité Económico y Social Europeo considera que la reducción de emisiones nocivas de monóxido de carbono, óxidos de nitrógeno, hidrocarburos y partículas provocadas por motores destinados a tractores agrícolas y forestales es un paso fundamental para lograr los niveles de calidad del aire establecidos por la UE, habida cuenta de las graves dudas que generan para la salud pública y para el medio ambiente las nanopartículas resultantes de los procesos de combustión.

La definición de las máquinas móviles no de carretera (en lo sucesivo, MMNC) incluye una amplia gama de máquinas y de motores de combustión. Estos motores están incorporados a equipos portátiles, pero también a máquinas que se mueven sobre ruedas, orugas y raíles. Se utilizan en la construcción, la agricultura, la minería, el ferrocarril, las vías navegables interiores y muchos otros sectores. Los límites de emisiones de estos motores se hallan actualmente definidos por la Directiva 97/68/CE. Cuando la Directiva se modificó en 2004 se introdujeron nuevas fases de emisiones. La conclusión de la Comisión Europea es que dicha Directiva no refleja ya el estado actual de la tecnología de las MMNC y, por lo tanto, debe ponerse en línea con los límites de emisiones vigentes para vehículos de carretera (por ejemplo, autobuses y camiones). Sin embargo, a diferencia de la normativa sobre emisiones en carretera, en la que se distingue entre los vehículos más pequeños y los más grandes, existiendo una normativa aparte para motocicletas, vehículos ligeros y pesados, las reglamentaciones para motores no de carretera son una propuesta general que pretende abarcar una gama enorme de máquinas y equipos. A tales efectos, es imprescindible rediseñar la normativa en esta materia. 